Preventative mechanisms can reduce the likelihood of perturbations by altering the environment to reduce conflicts of interest between parties, or to create dependencies that are beneficial. One explanation for the evolution of the arrest of meiosis, the process by which gametes are produced, is that early sequestering of the germline protects it by minimizing the total number of possible mutations. In this way, conflict is pre-emptively eliminated. Bradley Thayer, an expert in national security, suggests that the motivation behind the US policy of spreading 'effective democracy' is to change the environment from one that fosters extreme positions to one that is open to negotiation. By drawing on analogous processes in biology, one might show the conditions under which such policies are likely to work.

Robustness has its costs. The trade-off between robustness and the ability of a system to reconfigure into a new state when faced with a changed environment - known as evolvability - is poorly understood in evolutionary theory. The consequences for the evolvability of the mechanisms discussed in Natural Security are unknown, and these ideas should be adopted with caution. Modularity, for example, may allow reconfiguration and limit damage by decoupling the fates of components and providing a flexible architecture. However, coordinating the different parts can be costly and difficult to manage. In hunter-gatherer societies, the division of labour requires the building of a distribution system supported by exchange rules; if the rules are unclear or violated, then conflict can result. When components are too specialized, their ability to adopt other functions is sometimes lost, making the system less evolvable and less robust.

Natural Security is a stimulating read. It opens the door to an exciting merger between political science and evolutionary theory. The task now is to use the ideas of organizational robustness that are developing in evolutionary theory to formulate principled hypotheses about the consequences of national-security decisions. Jessica Flack is a research fellow at the Santa Fe Institute, 1399 Hyde Park Road, Santa Fe,

New Mexico 87501, USA.

\title{
Genetic medicine at the bedside
}

\author{
Heredity and Hope: The Case for Genetic \\ Screening \\ by Ruth Schwartz Cowan \\ Harvard University Press: 2008. 270 pp. \\ $\$ 27.95, £ 18.95$
}

Despite the fresh veneer of technology, medical genetics still follows the old-fashioned practice of medicine. It remains the most clinical of disciplines - in the literal sense, from the Greek klinikos, meaning 'of a bed' - in that most of the genetic physician's work is done at the bedside.

The story of the patient's illness, their family history and the physical examination remain the cornerstones of diagnosis. A clinician must examine the whole body to catalogue subtle and obvious signs and symptoms: the texture of the skin, how the ears are slung, the shape of the uvula in the back of the throat. Clinical findings then cohere, much like stars in constellations, into the eponymous syndromes with which we are familiar.

In Heredity and Hope, technology sociologist and historian Ruth Schwartz Cowan writes brief histories of several hereditary diseases and the scientists and clinicians who developed screening tests for them. Of the thousands of genetic diseases, Cowan focuses on a handful that are atypical in that they are well understood biochemically, genetically and sociologically.
These include Tay-Sachs disease and phenylketonuria, which result from enzyme deficiencies, and sickle-cell anaemia and $\beta$ thalassaemia, which arise from defects in $\beta$ haemoglobin, one of the most studied of all proteins. For each disease, the probability of clinical expression given a specific genotype is very high, making predictions reliable and early detection routine.

The consequences of these diseases remain devastating to patients and their families. This is especially true in the case of phenylketonuria, where a delayed diagnosis may result in irreversible brain damage. Physicians, parents, patients and insurance providers all agree on the benefits of identifying carriers of the mutant genes or diagnosing disease either in utero or at the time of birth, and identification protocols have been crafted that are acceptable to most. The greatest disagreements

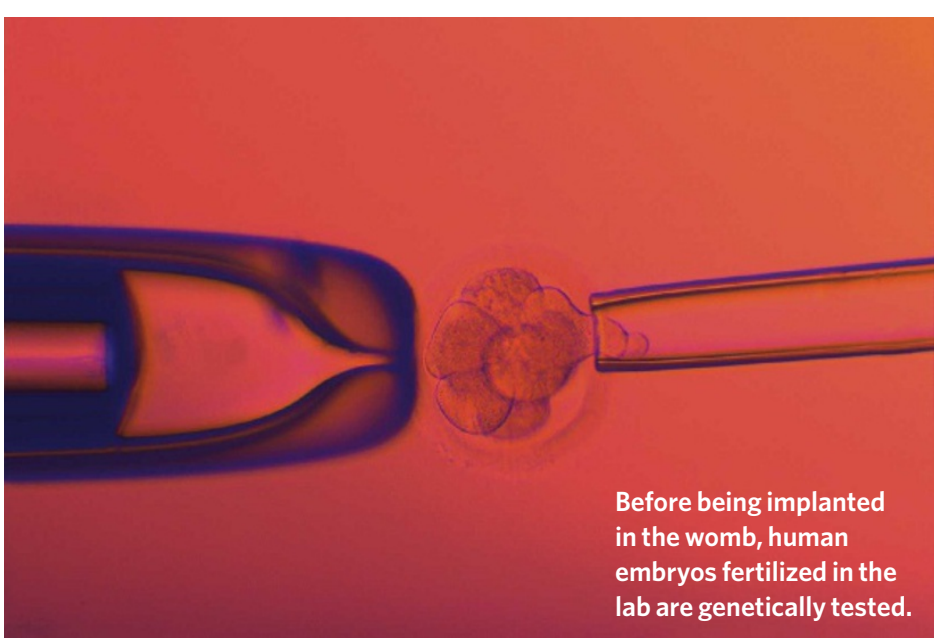

centre on what action to take once we have this genetic information.

The author's brief history of eugenics presses the point that medical genetics owes no apologies to society. There is no overlap between those who care for patients with genetic disease and anyone who has advocated the purification of the general germplasm through genetic isolation, including sterilization. This is obvious given that eugenics as public policy and as science met its deserved end in the first half of the twentieth century, whereas medical genetics as a sub-speciality formally began in the 1950s when Victor McKusick opened the Moore Clinic at the Johns Hopkins Hospital in Baltimore, Maryland.

That medical genetics and eugenics sprang from the same scientific soil has given ground to a small chorus of opponents to genetic screening. Trying to pull the ugly thread of eugenics through the fabric of genetics to discredit it, these opponents range from what Cowan calls 'reproductive feminists' to advocates of rights for people with disabilities, and span both the political left and right. This is not to dismiss the defensible reasons to object to population-based screening for specific diseases.

Clinical variability can be huge, even for specific genotypes, so the decision to establish a screening programme is not straightforward. Every medical geneticist has been confronted by the fluid meaning of disability. Despite clear clinical challenges, many deaf people, for example, do not consider themselves disabled and rightly 
resent being defined by their trait. Medical geneticists have had to adapt to patients' views of themselves.

To justify morally the genetic-screening programmes she writes about, Cowan cites the good intentions of the parties involved, primarily their efforts to relieve suffering. This criterion does not pass philosophical muster, nor is it sufficient to sway vehement opponents. Although her analysis is cursory, it does get to the heart of the matter: hereditary diseases cause great human suffering and everyone wants to help.

What no commentator on medical genetics acknowledges is the hidden sadness, customarily buried, that each geneticist feels when discussing with patients and parents the options for treatment, which are generally few and unsatisfactory. This takes its toll on everyone, although patients always astound with their resilience.

The hard truth is that genetics does not offer easy answers. There are many genetic diseases, and each one is unique. The simplicity of DNA is illusory - our DNA is popularly regarded as our medical fate, but DNA interrogations more often yield notions of risk that have different meanings to patients and physicians. Physicians rarely know the true cause of our complaints. In those genetic cases where simplicity prevails, the testing technology is likely to be adopted. As law in the United States, the Genetics Information Non-discrimination Act may relieve some anxiety about the misuse of genetic information. If only it were so simple to dispatch misery.

Modern healers may claim science to be the foundation of their work, but the key is, in fact, persuasion: to heed advice, to push and persevere, to hope. As the genome is further dissected and better understood, no family of diseases warrants more genuine hope for successful management than genetic conditions. Cowan understands that we must all share that hope for the campaign to be successful.

Hugh Young Rienhoff Jr is director of MyDaughtersDNA.org, based in San Francisco, California, USA.

\section{A rough guide to Titan}

\section{Titan Unveiled: Saturn's Mysterious Moon Explored by Ralph Lorenz and Jacqueline Mitton Princeton University Press: 2008. 296 pp. $\$ 29.95, £ 17.95$}

A future tourist guidebook to this remote destination would warn us to bring our heavyduty rain gear, but be prepared not to need it. Droughts may last many years there, but when a hurricane-sized storm sweeps across the sky, the rainfall is torrential. At high latitudes, the landscape is dotted with thousands of lakes, some mere ponds and others inland seas. Networks of channels and canyons are etched into the terrain, over which huge volcanic domes loom. Other regions harbour vast fields of dunes, some 100 metres high. Welcome to Titan, Saturn's largest moon.

Our guidebook would go on to explain that the dune particles are not sand, but hydrocarbons, totalling more than all the coal reserves on Earth. The magma flowing from the volcanoes is not liquid rock, but a mix of ammonia and water, similar to antifreeze. Liquid ethane fills the lakes. And liquid methane carved the gullies at rates far in excess of the worst flash-flooding on Earth.

Titan Unveiled, by planetary scientist Ralph Lorenz and astronomy writer Jacqueline Mitton, presents a good overview of the state of our knowledge of this curious moon, and is accessible to most. Lorenz is closely involved with the Cassini mission to Saturn and the Huygens probe it dropped onto Titan's surface in 2005. The book focuses on his key interests, which include Titan's surface and lower atmosphere, regions that parallel Earth and are thus the most engaging for readers.

Titan Unveiled describes how most of what we once hypothesized about Titan has been proved wrong. The story of how we gained our current knowledge is fascinating; even more intriguing is what remains to be learned. Larger than Mercury, Titan is the only moon in our Solar System that is enveloped in a thick atmosphere. Analogous to Earth's water-based weather system, Titan's atmosphere experiences weather based on the phase changes of methane, shifting between its gas, liquid and solid states. At the extremely cold temperatures on Titan's surface $\left(94 \mathrm{~K}\right.$, or $\left.-179^{\circ} \mathrm{C}\right)$, water is frozen and acts like rock. The moon is geologically active, including volcanism and uplifting of mountain ranges. Deep under the icy surface, evidence for an ocean of liquid water and ammonia has been found.

Scattered throughout the text are personal anecdotes by Lorenz, labelled "Ralph's Log". Key to the book's success, these sections

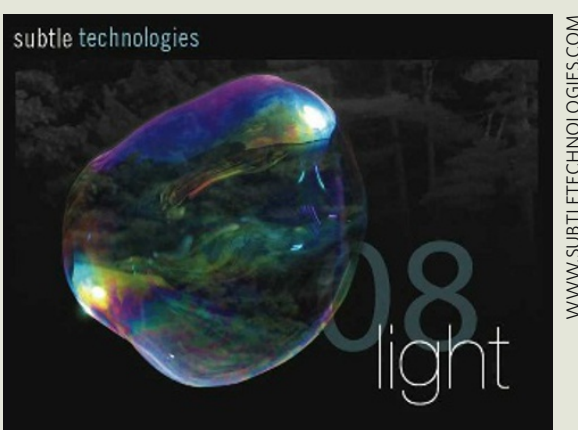

\section{NORTHERN LIGHTS}

The many shades of light in art and science are the focus of the annual Subtle Technologies Festival in Toronto, Canada, starting this week. A symposium (from 30 May to 1 June) will discuss the physics of light, its use in education, photography, performance, new media and architecture. Sound artists muse about synaesthesia; a physicist explains why painters love the light in Provence, France; and a biologist describes how to image cells.

www.subtletechnologies.com

\section{GREEN FINGERS}

Gardeners are the canaries of climate change: first to notice buds blooming early, lawns that need mowing more often and pests spreading in range as average temperatures creep up. This week's Chelsea Flower Show in London (until 24 May), run by the Royal Horticultural Society, includes scientific exhibits to educate plant lovers about climate change. UK researchers from the Tyndall Centre in Norwich, the University of Reading, Rothamsted Research in Harpenden, and others will be on hand to explain how plants, ecosystems and practices must adapt. www.rhs.org.uk/chelsea/2008

\section{BEING HUMAN}

An exploration of what it means to be human in a rapidly changing world and vast Universe is the theme of the 55th Carnegie International. The largest US survey of contemporary art, it opened this month at Pittsburgh's Carnegie Museum of Art (until January 2009). Life on Mars, named after David Bowie's song, offers 300 works from 40 international artists, including Vija Celmins, who received the US\$10,000 Carnegie Prize for her Night Sky series of paintings.

www.cmoa.org

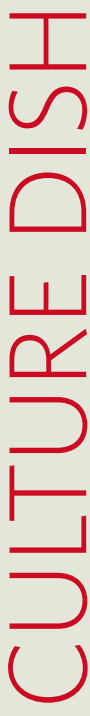

